\title{
Nano-isocyanurate-Periodic mesoporous organosilica (PMO): a heterogeneous catalyst for three-component synthesis of tetrahydrobenzo[b]pyrans in water
}

\author{
Mohammad G. Dekamin*, Alireza Rezazadeh-Shendabadi, Abulfazl Seyedsadjadi, Amene Yaghoubi \\ Department of Chemistry, Iran University of Science and Technology, Pharmaceutical and Biologically-Active \\ Compounds Research Laboratory, Tehran, Iran. \\ mdekamin@iust.ac.ir
}

\begin{abstract}
Isocyanurate containing periodic mesoporous organosilicas (ICS-PMO) without any post-modification was used as a novel heterogeneous catalyst for synthesis of tetrahydrobenzo[b]pyran derivatives via one-pot threecomponent condensation of aromatic aldehydes with malononitrile (or ethyl cyanoacetate) and dimedone. The catalyst was characterized by FT-IR Spectroscopy, TEM, SEM and BET techniques. Products were obtained in short reaction times with excellent yields in water under reflux conditions. The catalyst could be recycled and reused for several times without noticeably decreasing the catalytic activity.
\end{abstract}

Keywords: Green chemistry Heterogeneous catalyst; PMO; Tetrahydrobenzo[b]pyran derivatives; Synthesis in water.

\section{Introduction}

Green chemistry can be recognized as a pioneering approach, which widely reports intrinsic atom economy, energy savings, waste reduction, easy workups, and the avoidance of hazardous chemicals [1]. In this context, the efficiency of heterogeneous catalysis in organic synthesis could be considerably improved by employing nano-sized catalysts due to their extremely small size and large surface to volume ratio [2]. The development of environmentally benign, efficient, and economical methods for the synthesis of biologically interesting compounds remains a significant challenge in synthetic chemistry [3]. Along this line, PMOs have received great attention as heterogeneous catalysts. A PMO is a special type of hybrid organic-inorganic materials, in which organic moieties are integrated into the silica framework. PMOs can be synthesized by using various structure directing agents such as ionic surfactants, oligomeric surfactants, and nonionic block copolymers. Because of uniform distribution of organic bridging groups inside mesopore walls, PMOs become very promising materials for potential applications ranging from highly selective adsorbents and catalysts to sensing devices and hosts for biomolecules.

On the hand, water has been applied in organic reaction as solvent, and it has several advantages such as low cost, safety, non-polluting nature, and operational simplicity [4]. Furthermore, tetrahydrobenzo $[b]$ pyran derivatives are an important

class of heterocyclic compounds having important pharmaceutical and biological activity. These compounds are used as anticancer, anticoagulant, diuretic, spasmolytic, and, etc [5]. Realizing the importance of $4 \mathrm{H}$-pyran derivatives, several synthetic methods have been reported with the aim of obtaining more biologically potent heterocyclic systems using different catalysts including nano-sized magnesium oxide [6], silica-bonded 1,4-diazabicyclo [2.2.2]octane [7], silica nanoparticles [8], electro generated base, baker's yeast, and aminofunctionalized ionic liquid. Other synthetic methods contain of microwaves, ultrasonic radiation, and utilizing additives like hexadecyltrimethylammonium bromide, triethylbenzylammonium chloride, other alkylammonium salts, 4-dodecylbenzenesulfonic acid, and $(S)$ - proline. However, limitations of the above methods include poor yields, difficult work-up, and toxic elements. We report herein the synthesis of isocyanurate-PMO (PMO-ICS) as a new catalysis and its application in the synthesis of pyran derivatives (Scheme 1).

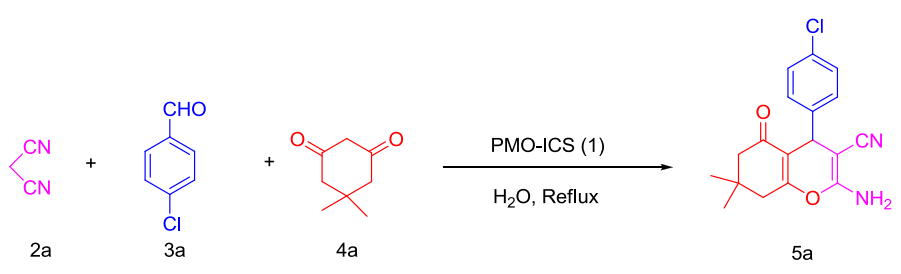


Scheme 1 Three-component reaction of malononitrile (2a), 4-chlorobenzaldehyde (3a), and dimedone (4a)

\section{Preparation of isocyanurate-PMO}

1 mmol of 1,3,5-tris(2-hydroxy ethyl)isocyanurate and $2 \mathrm{mmol}$ of 4-toluenesulfonyl chloride were poured in a test tube and then dry acetone was added as solvent. This tube was placed in an ultrasonic bath at $60^{\circ} \mathrm{C}$ for one hour. In the next stage, MCM-41 (261 mg) was added to test tube and then the reaction mixture was sonicated at $60^{\circ} \mathrm{C}$ for 1 hour. The obtained white solid was filtered and dried at $60^{\circ} \mathrm{C}$ over night

\section{Preparation of $4 \mathrm{H}-$-benzo[b]pyran derivatives}

A mixture of aromatic aldehydes $(1.0 \mathrm{mmol})$, malononitrile $(1.0 \mathrm{mmol})$, dimedone $(1.0 \mathrm{mmol})$, and $0.01 \mathrm{~g}$ isocyanurate containing PMO was stirred under reflux conditions in water. Progress of the reaction was monitored by TLC. After completion of the reaction, mixture was filtered for separation of heterogeneous catalyst.

\section{Results and Discussion}

The IR spectrum of isocyanurate-PMO indicates the $\mathrm{CH}$-stretching mode at 2854 and $2926 \mathrm{~cm}^{-1}$ and the mode of amidic carbonyl groups related to incorporation of isocyanurate substitution at $1689 \mathrm{~cm}^{-}$ ${ }^{1}$ as well comparatively long peak of Si-O-Si bindings at $1078 \mathrm{~cm}^{-1}$.

Only a trace amount of the favorable product was obtained under solvent-free conditions even at $100{ }^{\circ} \mathrm{C}$ (Table 1 entries1-2). We began to detect the catalytic activity of different amounts of 1, 3, 5- Tris (2hydroxy ethyl) isocyanurate. An excellent yield was obtained with $8 \mathrm{~mol} \%$. The presence of higher amounts of catalyst did not produce higher yields (entries 3-5). Then we investigated the performance of 8 mol\% of 1, 3, 5- Tris (2-hydroxy ethyl) isocyanurate to catalyze the reaction in different organic solvents (Table 1 entries 6-11). It is noteworthy to mention that $\mathrm{H}_{2} \mathrm{O}$ showed the best result.

Table 1 Optimization of the three-component reaction of dimedone, 4-chlorobenzaldehyde and malononitrile under various conditions ${ }^{\text {a. }}$.

\begin{tabular}{llllll}
\hline Entry & $\begin{array}{c}\text { Amount of } \\
\text { Catalyst }(\mathrm{mol} \%)\end{array}$ & Solvent & $\begin{array}{c}\text { Temp. } \\
\left({ }^{\circ} \mathrm{C}\right)\end{array}$ & $\begin{array}{r}\text { Yield }^{b} \\
(\%)\end{array}$ & Time/min \\
\hline 1 & - & - & - & Trace & $8 \mathrm{~h}$ \\
2 & - & - & 100 & Trace & $8 \mathrm{~h}$ \\
3 & 8 & $\mathrm{H}_{2} \mathrm{O}$ & Reflux & 92 & 17 \\
4 & 3 & $\mathrm{H}_{2} \mathrm{O}$ & Reflux & 80 & 30 \\
5 & 12 & $\mathrm{H}_{2} \mathrm{O}$ & Reflux & 92 & 17 \\
6 & 8 & $\mathrm{Aceton}$ & Reflux & 50 & 50 \\
7 & 8 & $\mathrm{CCl}_{4}$ & Reflux & 60 & 40 \\
8 & 8 & $\mathrm{DMS}$ & Reflux & 50 & 90 \\
9 & 8 & $\mathrm{CHCl}_{3}$ & reflux & 50 & $3 \mathrm{~h}$ \\
10 & 8 & - & - & 60 & 30 \\
11 & 8 & - & 70 & 85 & 40 \\
& & $\mathrm{H}_{2} \mathrm{O}$ & & & \\
\hline
\end{tabular}

Both aromatic carbocyclic and heterocyclic aldehydes containing electron-withdrawing and electrondonating groups underwent this condensation to furnish tetrahydrobenzo[ $b]$ pyrans in high to excellent yields ( Table 2).

Table 2 Synthesis of derivatives of 2-amino-5-oxo-5,6,7,8tetrahydro-4H-benzo[b]pyran (5) via condensation of dimedone or 1,3-cyclohexanedione, different aldehydes and malononitrile in the presence of PMO-ICS.

\begin{tabular}{|c|c|c|c|c|}
\hline Entry & RCHO & product & Time(min) & $\begin{array}{c}\text { Yield } \\
(\%)\end{array}$ \\
\hline 1 & $4-\mathrm{ClC6H} 4$ & $5 \mathrm{a}$ & 17 & 92 \\
\hline 2 & $4-\mathrm{O} 2 \mathrm{NC6H} 4$ & $5 \mathrm{~b}$ & 12 & 85 \\
\hline 3 & $\mathrm{C6H6}$ & $5 \mathrm{c}$ & 23 & 93 \\
\hline 4 & $4-\mathrm{MeC6H4}$ & $5 \mathrm{~d}$ & 17 & 92 \\
\hline
\end{tabular}

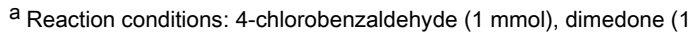
$\mathrm{mmol}$ ), malononitrile (1 $\mathrm{mmol})$, water $(3 \mathrm{~mL})$

${ }^{\mathrm{b}}$ Isolated Yield
} 


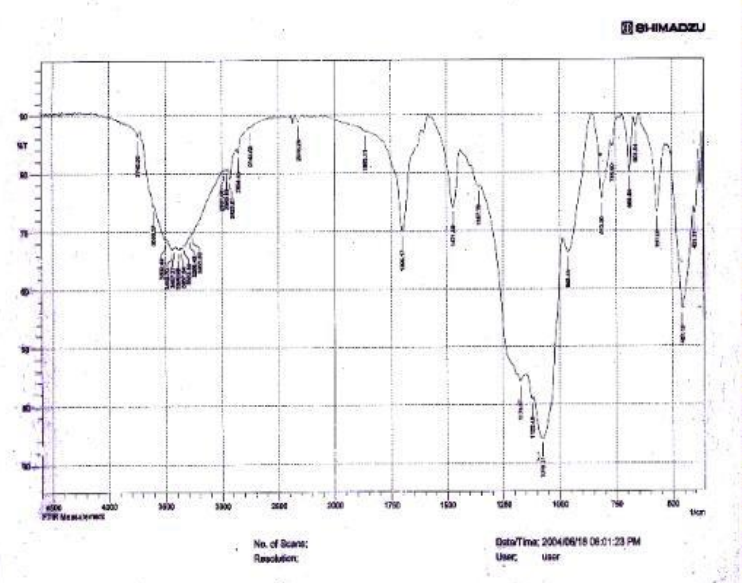

Fig 1 IR spectrum of isocyanurate containing PMO

The surface area and pore diameter obtained 1545.96 and $2.6 \mathrm{~nm}$ respectively, using BET analysis was shown in fig 2.

\section{Conclusions}

In summary, PMO-ICS were prepard by grafting 1, 3, 5-tris (2-hydroxyethyl) isocyanurate into the inner surface of the wall by helping ultrasonic waves. This compound used as heterogeneous catalyst for threecomponent one-pot synthesis of tetra hydro benzo[b]pyrans in water. The advantages this work short reaction time, excellent yield, recyclability and reusability of catalysis, and the use of water as a green solvent.

\section{Acknowledgment}

The authors thank the Research Committee of Iran University of Science and Technology, for financial support of this work.

\section{References}

[1] M. Shafiee, R. Moloudi, M. Ghashang, " $Z n O$ Nano powder An Efficient Catalyst for the Preparation of 2,4,6-Triaryl Pyridines under Solvent-Free Condition”, Tetrahedron, 2012, 221-225.

[2] N. Hazeri, T. Maghsoodlu, F. Mir, M. Mangani, H. Saravani, "An efficient one-pot three component synthesis of tetrahydro benzo[b]pyran and 3,4-dihydro pyrano $[c]$ chromene derivatives using starch solution as catalyst", J. Catal., 2014, 391-395.

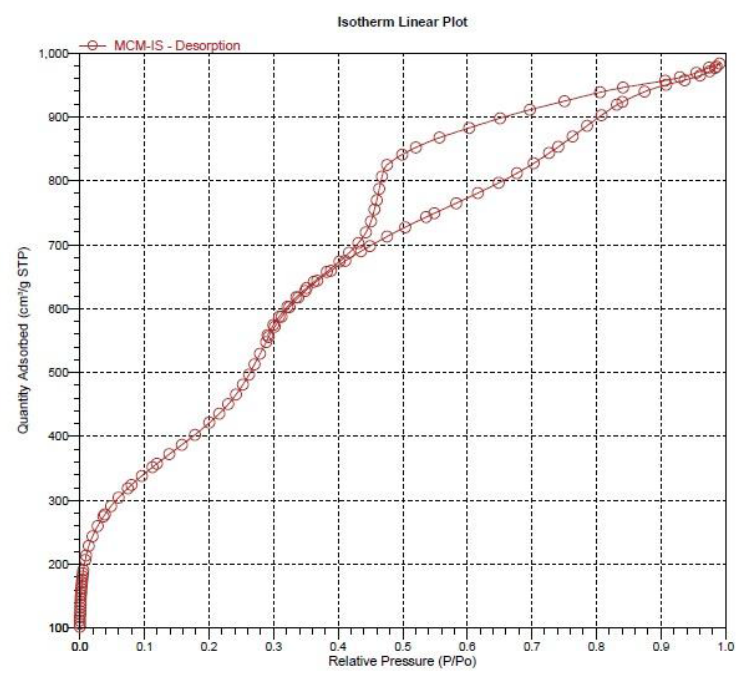

Fig 2 BET analysis of PMO-ICS

[3] A. Kumar, M. Kumar gupta, M. Kumar, "L-Proline catalysed multicomponent synthesis of 3-amino alkylated indoles via a Mannich-type reaction under solvent-free conditions", green chem., 2012, 290-295.

[4] C. Junli, L. Chen, "Organic chemistry in water", 2006, chem. Soc., p. 68.

[5] M. Dekamin, M. Eslami, A. Maleki," Potassium phthalimide- N-oxyl: a novel, efficient, and simple organocatalyst for the one-pot three-component synthesis of various 2-amino-4H-chromene derivatives in water", Tetrahedron, 2013, 1074-1085.

[6] Sh. Zhang, Sh. Feng yin, Y. Wei, Sh. Lian luo," Novel $\mathrm{MgO}-\mathrm{SnO} 2$ Solid Super base as a High Efficiency Catalyst for One-Pot Solvent-Free Synthesis of Polyfunctionalized 4H-pyran Derivatives", Tetrahedron, 2012, 608-614.

[7] A. Hasaninejad, N. Jafarpour, M. Mohammadnejad," Synthesis of Benzo[b]pyrane Derivatives Using Supported Potassium Fluoride as an Efficient and Reusable Catalytic System", J. Catal., 2011, 2000-2005.

[8] A. Ziarati, J. Safaei-ghomi, S. Rohani," Sonochemically synthesis of pyrazolones using reusable catalyst $\mathrm{CuI}$ nanoparticles that was prepared by sonication", Ultrasonics sonochemistry, 2013, 1065-1079 